(1)

CrossMark

\title{
Age, risk and outcomes in idiopathic pulmonary arterial hypertension
}

\author{
Marius M. Hoeper ${ }^{1,2}$, Athénaïs Boucly $y^{3,4,5}$ and Olivier Sitbon (103,4,5 \\ Affiliations: ${ }^{1}$ Dept of Respiratory Medicine, Hannover Medical School, Hannover, Germany. ${ }^{2}$ German Centre of \\ Lung Research (DZL), Germany. ${ }^{3}$ Université Paris-Sud, Faculté de Médecine, Université Paris-Saclay, Le \\ Kremlin-Bicêtre, France. ${ }^{4}$ AP-HP, Service de Pneumologie, Hôpital Bicêtre, Le Kremlin-Bicêtre, France. \\ ${ }^{5}$ INSERM UMR_S 999; Hôpital Marie Lannelongue, Le Plessis Robinson, France. \\ Correspondence: Marius M. Hoeper, Dept of Respiratory Medicine, Hannover Medical School, 30623 \\ Hannover, Germany. E-mail: hoeper.mariusamh-hannover.de
}

@ERSpublications

Older patients with IPAH often present with distinct phenotypes and show less improvements with targeted therapy than younger patients http://ow.ly/vsCb30jqOB3

Cite this article as: Hoeper MM, Boucly A, Sitbon O. Age, risk and outcomes in idiopathic pulmonary arterial hypertension. Eur Respir J 2018; 51: 1800629 [https://doi.org/10.1183/13993003.00629-2018].

The current European pulmonary hypertension (PH) guidelines recommend a risk-based therapeutic approach to patients with idiopathic pulmonary arterial hypertension (IPAH) [1, 2]. The goal is reaching and maintaining a low risk profile. Recent studies from the French $\mathrm{PH}$ registry and from the European $\mathrm{PH}$ registry COMPERA have confirmed that IPAH patients who meet 3-4 distinct low risk criteria with targeted therapies have 5 -year survival rates of $95 \%$ or higher $[3,4]$. Unfortunately, this was accomplished only in $19 \%$ of the patients in the French series and $9 \%$ of the patients in COMPERA $[4,5]$. The reasons why the majority of patients fail to reach a low risk profile with targeted therapies have not been fully explored.

In this issue of the European Respiratory Journal, HJALMARSSON et al. [6] present data from the Swedish PH registry showing that the likelihood that IPAH patients meet a low risk profile with targeted therapies diminishes with increasing age. Almost $80 \%$ of patients aged between 18 and 45 years reached the low risk category with PAH treatment, compared with approximately $20 \%$ of patients aged $\geqslant 65$ years and less than $10 \%$ of patients aged $\geqslant 75$ years. Improvements in risk category were rarely observed in patients aged $\geqslant 65$ years. Similar data have been recently reported from COMPERA [3]. In the present Swedish series, the 5-year transplantation-free survival decreased from $88 \%$ in patients aged $18-45$ years to $36 \%$ in patients aged $\geqslant 75$ years.

The high mortality risk of older IPAH patients is probably due to various reasons including comorbidities, unique disease phenotypes, different treatment patterns, and a diminished response to PAH targeted therapies. These factors are tightly interconnected but can be assessed separately.

\section{Increasing age and mortality in IPAH}

The mean age of patients enrolled between 1981 and 1985 in the US National Institutes of Health (NIH) registry was 36 years at the time of diagnosis; only $9 \%$ of the patients were more than 60 years of age [7]. Since then, the age of IPAH patients has increased considerably, at least in Western countries [4, 8-11]. In Germany, the mean age of patients newly diagnosed with IPAH in 2014 was 65 years [12]. In a recent Swedish registry, the mean age at diagnosis was 69 years [13]. Naturally, older patients have a higher mortality risk in general, but it has already been shown that older patients ( $>65$ years) diagnosed with IPAH have a significantly higher mortality risk than younger patients (18-65 years), even when adjusted for their respective statistical life expectancies [14]. 


\section{Comorbidities and disease phenotypes}

Not unexpectedly, increasing age in the Swedish cohort was accompanied by a higher prevalence of comorbidities, in particular systemic hypertension, diabetes mellitus, coronary heart disease, atrial fibrillation and renal insufficiency. All these comorbidities are known to increase the risk of death. Coronary heart disease and renal insufficiency were independent predictors of mortality in the Swedish IPAH cohort. The high prevalence of these comorbidities among older patients diagnosed with IPAH raise the questions whether these patients truly suffer from IPAH, or whether at least some of them actually have $\mathrm{PH}$ due to left heart disease, in particular heart failure with preserved ejection fraction (HFpEF). The normal pulmonary artery wedge pressure (PAWP; mean $9 \mathrm{mmHg}$ ) in the Swedish patients does not rule out HFpEF, which can present with normal PAWP levels at rest [15]. There is as yet no consensus among experts about how to best classify these patients $[15,16]$.

Another striking feature of the Swedish cohort was a male predominance among older patients with IPAH, while the younger patients were predominantly female, as has been seen in various previous series [7-9]. Several groups have recently reported on a distinct IPAH phenotype of mostly elderly male patients with precapillary $\mathrm{PH}$, a history of smoking, no signs of parenchymal lung disease, but a low diffusion capacity of the lung for carbon monoxide (DLCO) [17-19]. Those patients respond poorly to PAH therapies and have an exceptionally high mortality risk [19]. In the Swedish cohort, DLCO was also significantly lower in the older patients, probably indicating that this cohort included patients with this unique "low diffusion capacity" phenotype that could suggest pulmonary capillary and vein involvement.

Today, IPAH is no longer a relatively homogeneous disease affecting mostly younger patients, but a condition where new phenotypes have been emerging predominantly, but not exclusively, among older patients. We do not even know if what we call IPAH in older patients presenting with the phenotypes described above is the same disease as the "classic" form of IPAH that we used to see back in the days of the US NIH registry, and that we still see today, albeit less frequently than older patients with more complex disease phenotypes.

\section{Treatment and treatment response}

Perhaps the most important clue to the findings by HJALMARSSON et al. [6] is a better understanding of how older patients respond to PAH targeted therapies. Such patients were not well represented in PAH studies. Some of the recent clinical trials in PAH had an upper age limit of 75 years, and the average age of the enrolled patients ranged from 48 to 54 years $[20,21]$. Hence, most of the available data on treatment responses in older patients have been derived from registries. OpITz et al. [22] have shown recently that older patients diagnosed with IPAH 1) often present with risk factors for left heart disease, 2) have little clinical improvement with PAH targeted therapies, 3) frequently experience side-effects and drug discontinuations due to side-effects when exposed to PAH targeted therapies, and 4) usually do not receive combination therapies or parenteral prostacyclin analogues. The present findings from Sweden confirm and expand these observations.

The current study from Sweden does not come without limitations. Registries usually do not have the quality of rigorous clinical studies, and missing data, as well as incorrect data entries, may have affected the results. The age stratification was arbitrary and other stratifications may have yielded different results. The sample size was relatively small ( $n=264$ at baseline; $n=220$ with follow-up visits), and follow-up right heart catheterisation data were available for only 87 patients. Despite these limitations, this study adds to our understanding of treatment responses in older patients with IPAH and highlights the need to look further into this patient population.

Taken together, the increasing age of patients diagnosed with IPAH and the accompanying clinical features have substantial impact on clinical practice. Clinical trials in the PAH field have enrolled mostly younger patients with a "classical" phenotype and few comorbidities. Risk assessment and risk-based treatment strategies have been developed and validated primarily for these patients. There is, however, a considerable gap between clinical trial populations and real-world patients. Registry data show that PAH drugs are widely used in older patients with multiple comorbidities, but little is known about their safety and efficacy in these patients. The present paper by HJalmarsson et al. [6] reinforces this notion by demonstrating absence of substantial clinical improvements in the majority of older IPAH patients receiving PAH therapies. Registry data help to better characterise and understand these patients, but eventually, adequate representation in randomised trials is necessary to determine the best possible care for this increasingly relevant group of patients.

Conflict of interest: M.M. Hoeper has received fees for lectures and/or consultations from Actelion, Bayer, Gilead, GSK, MSD and Pfizer. A. Boucly has received fees for lectures from Actelion, and non-financial support from Actelion, Bayer, 
GSK and Merck. O. Sitbon has received grants and/or personal fees and/or non-financial support from Actelion, Bayer, GSK, Merck and Arena Pharmaceuticals.

\section{References}

1 Galie N, Humbert M, Vachiery JL, et al. 2015 ESC/ERS Guidelines for the diagnosis and treatment of pulmonary hypertension: The Joint Task Force for the Diagnosis and Treatment of Pulmonary Hypertension of the European Society of Cardiology (ESC) and the European Respiratory Society (ERS). Eur Respir J 2015; 46: 903-975.

2 Galie N, Humbert M, Vachiery JL, et al. 2015 ESC/ERS Guidelines for the diagnosis and treatment of pulmonary hypertension. Eur Heart J 2016; 37: 67-119.

3 Hoeper MM, Pittrow D, Opitz C, et al. Risk assessment in pulmonary arterial hypertension. Eur Respir J 2018; 51 : 1702606.

4 Boucly A, Weatherald J, Savale L, et al. Risk assessment, prognosis and guideline implementation in pulmonary arterial hypertension. Eur Respir J 2017; 50: 1700889.

5 Hoeper MM, Kramer T, Pan Z, et al. Mortality in pulmonary arterial hypertension: prediction by the 2015 European pulmonary hypertension guidelines risk stratification model. Eur Respir J 2017; 50: 1700740.

6 Hjalmarsson C, Rådegran G, Kylhammar D, et al. Impact of age and comorbidity on risk stratification in idiopathic pulmonary arterial hypertension. Eur Respir J 2018; 51: 1702310.

7 Rich S, Dantzker DR, Ayres SM, et al. Primary pulmonary hypertension. A national prospective study. Ann Intern Med 1987; 107: 216-223.

8 Badesch DB, Raskob GE, Elliott CG, et al. Pulmonary arterial hypertension: baseline characteristics from the REVEAL Registry. Chest 2010; 137: 376-387.

9 Humbert M, Sitbon O, Chaouat A, et al. Pulmonary arterial hypertension in France: results from a national registry. Am J Respir Crit Care Med 2006; 173: 1023-1030.

10 Ling Y, Johnson MK, Kiely DG, et al. Changing demographics, epidemiology, and survival of incident pulmonary arterial hypertension: results from the pulmonary hypertension registry of the United Kingdom and Ireland. Am J Respir Crit Care Med 2012; 186: 790-796.

11 Frost AE, Badesch DB, Barst RJ, et al. The changing picture of patients with pulmonary arterial hypertension in the United States: how REVEAL differs from historic and non-US contemporary registries. Chest 2011; 139: $128-137$.

12 Hoeper MM, Huscher D, Pittrow D. Incidence and prevalence of pulmonary arterial hypertension in Germany. Int J Cardiol 2016; 203: 612-613.

13 Radegran G, Kjellstrom B, Ekmehag B, et al. Characteristics and survival of adult Swedish PAH and CTEPH patients 2000-2014. Scand Cardiovasc J 2016; 50: 243-250.

14 Hoeper MM, Huscher D, Ghofrani HA, et al. Elderly patients diagnosed with idiopathic pulmonary arterial hypertension: Results from the COMPERA registry. Int J Cardiol 2013; 168: 871-880.

15 Vachiery JL, Adir Y, Barbera JA, et al. Pulmonary hypertension due to left heart diseases. J Am Coll Cardiol 2013; 62: Suppl. 25, D100-D108.

16 Borlaug BA, Obokata M. Is it time to recognize a new phenotype? Heart failure with preserved ejection fraction with pulmonary vascular disease. Eur Heart J 2017; 38: 2874-2878.

17 Trip P, Nossent EJ, de Man FS, et al. Severely reduced diffusion capacity in idiopathic pulmonary arterial hypertension: patient characteristics and treatment responses. Eur Respir J 2013; 42: 1575-1585.

18 Hoeper MM, Vonk-Noordegraaf A. Is there a vanishing pulmonary capillary syndrome? Lancet Respir Med 2017; 5: 676-678.

19 Olsson KM, Fuge J, Meyer K, et al. More on idiopathic pulmonary arterial hypertension with a low diffusing capacity. Eur Respir J 2017; 50: 1700354.

20 Galie N, Barbera JA, Frost AE, et al. Initial use of ambrisentan plus tadalafil in pulmonary arterial hypertension. N Engl J Med 2015; 373: 834-844.

21 Sitbon O, Channick R, Chin KM, et al. Selexipag for the treatment of pulmonary arterial hypertension. $N$ Engl J Med 2015; 373: 2522-2533.

22 Opitz CF, Hoeper MM, Gibbs JS, et al. Pre-capillary, combined, and post-capillary pulmonary hypertension: a pathophysiological continuum. J Am Coll Cardiol 2016; 68: 368-378. 